Indexed by \title{
MODELING OF THE PROCESS OF COLLECTION,
Scopus
SORTING AND TRANSPORTATION OF LOGGING RESIDUES AT THE LOGGING AREA
}

Crossref

KOBSON

gil Google

\section{Aleksandr Mokhirev}

Reshetnev Siberian State

University of Science and Technology, Lesosibirsk Branch, Department of technology of logging and wood processing industries, Lesosibirsk, Russia

\section{Tatiana Rjabova}

Reshetnev Siberian State University of Science and Technology, Lesosibirsk Branch, Department of economic and natural sciences, Lesosibirsk, Russia

\section{Mihail Zyrjanov}

Reshetnev Siberian State

University of Science and

Technology, Lesosibirsk Branch, Department of engineering and technical systems, Lesosibirsk, Russia
Sergey Medvedev

Reshetnev Siberian State University of Science and Technology, Lesosibirsk Branch, Department of economic and natural sciences, Lesosibirsk, Russia

Key words: logging technology, recycling of felling residues, logging residues, harvester, forwarder, sorting of logging residues, information and logical model of the process, modeling of technological process

Cite article:

Aleksandr, M., Mihail, Z., Sergey, M., \& Tatiana, R. [2021]. Modeling of the process of collection, sorting and transportation of logging residues at the logging area. Journal of Applied Engineering Science, 19(1) 114 - 118. DOI:10.5937/jaes0-25673

Online aceess of full paper is available at: www.engineeringscience.rs/browse-issues 


\title{
MODELING OF THE PROCESS OF COLLECTION, SORTING AND TRANSPORTATION OF LOGGING RESIDUES AT THE LOGGING AREA
}

\author{
Aleksandr Mokhirev ${ }^{1 *}$, Mihail Zyrjanov ${ }^{2}$, Sergey Medvedev ${ }^{3}$, Tatiana Rjabova ${ }^{3}$ \\ ${ }^{1}$ Reshetnev Siberian State University of Science and Technology, Lesosibirsk Branch, \\ Department of technology of logging and wood processing industries, Lesosibirsk, Russia \\ ${ }^{2}$ Reshetnev Siberian State University of Science and Technology, Lesosibirsk Branch, \\ Department of engineering and technical systems, Lesosibirsk, Russia \\ ${ }^{3}$ Reshetnev Siberian State University of Science and Technology, Lesosibirsk Branch, \\ Department of economic and natural sciences, Lesosibirsk, Russia
}

Effectiveness of economic development of logging industry is impossible without scientifically grounded strategies of formation of perspective technological logging processes with complex use of the total biomass of harvested trees. Degree of utilization of wood biomass is to be considered the most important principle of progressive logging technology. One of the main tasks of the national logging complex is the use of low-grade wood, lumpy wood waste, top of trees, twigs and branches, which will significantly improve efficiency of logging. To solve this problem, this article reviews the process of modeling of work of sorting and transportation machine designed for loading, sorting and transportation of felling residues to timber road. The technological scheme also provides cutting waste with knife for sorting by size. The study provides a detailed technological scheme of logging operations using forwarders with a removable body for loading, sorting and transportation of felling residues. The body of the forwarder is divided into compartments for transportation of waste with different parameters. The information and logical model of the process of collection, sorting and transportation of felling residue, which is proposed by machine, was offered. The formula for calculating the performance of operation of the sorting and transportation machine was obtained. Sorting according to species and types of felling residues is necessary for the production of fuel and technological wood chips for further use in production of valuable commercial products.

Key words: logging technology, recycling of felling residues, logging residues, harvester, forwarder, sorting of logging residues, information and logical model of the process, modeling of technological process

\section{INTRODUCTION}

Currently, when the requirement for wood is constantly increasing, its integrated use assumes particular importance. Meeting the needs of the national economy in timber in the coming years will be implemented due to economical and most complete its use [1].

In this regard, the main focus of logging development is the improvement of the use of all cut wood pulp. It requires further improvement of production of logging and wood-processing industry, development of production of technological wood chips, wood boards, plywood, containerboard and other substitutes for timber [2].

Improving the use of wood biomass, the involvement in the recycling of low-grade, low-value wood, logging residues, waste, timber and wood recycling is a very important task.

The problem of waste recycling in logging has been reviewed by many domestic and foreign scientists in published various kinds of materials [3] - [6]. However, the proposed technologies were not applied widely in logging industry. The low quality, low demand and relatively high cost of the products received from waste recycling are the main reasons for the lack of attention to the waste pro- cessing of timber and wood- processing industry [7]. To address these shortcomings a number of activities, including the improvement of technological processes of cutting, transportation and recycling of wood biomass, has been proposed [8], [9]. Most proposed technological processes of timber recycling of are based on the production of fuel chips. Using this raw material it is possible to produce various chemical products and pulp and paper products [10] - [12]. However, different chemical composition, geometric characteristics and other parameters of felling residues of different species and types make the production of valuable commercial products impossible without sorting. The wood should be sorted for more efficient use of wood residuals [13].

\section{THEORY AND EXPERIMENTAL}

The aim of the research is the modelling of the process of operation of machines for sorting and transportation of logging residues at the cutting area. The following tasks were set therefore: to describe the process of collecting, sorting and transporting of felling residues from the place of felling and cross cutting to the loading point, make information and logical model of operation of the machine and derive the formula of the performance depending on the 
parameters of the subject of work for further optimization of the production process that involved operation of the machine.

The most common current technology of logging is the assortment with the use of harvesters and forwarders [14], [15]. Operation of harvester includes felling, limbing, cross cutting, sorting of received logs and bundling. Sorting of assortments is carried out according to criteria of commercial products that are to be derived. The harvester determines the geometric characteristics (length, diameter) of the assortments and they are indicated on the computer monitor of the machine. The operator visually assesses species and defects. Comparing the characteristics of the assortment obtained to the criteria for commercial products, the operator determines the type of product obtained. After cross cutting, assortments are stacked separately in different bundles. Felling residues shall be placed on or near the skid road without further processing. The forwarder collects sorted wood, stacks it on a loading platform using a hydraulic manipulator and transports it to a loading point, where it unloads the wood into a pile [16].

When harvesting wood with a complex of machines consisting of a harvester and a forwarder, the logging residues are located on a skid road in small heaps. In most cases, they are left on a skid road for further decay or burned in a fireproof period. It is proposed to use a sorting transportation machine made on the basis of a forwarder for its collection and sorting of logging residues. The technological scheme of logging operations proposed by the author is shown in Figure 1.

The harvester cuts tree, cuts branches and cuts it into assortments. Felling residues that are suitable for further processing are laid on the border of the skid road and swath in the process of limbing and cross cutting. Having collected commercial assortments, the forwarder reequips the body for the collection and sorting of logging residues (Fig. 2.). Logging residues (during collection) are being stored into different body compartments with the help of a manipulator depending on the further purpose, size, quality and species characteristics.

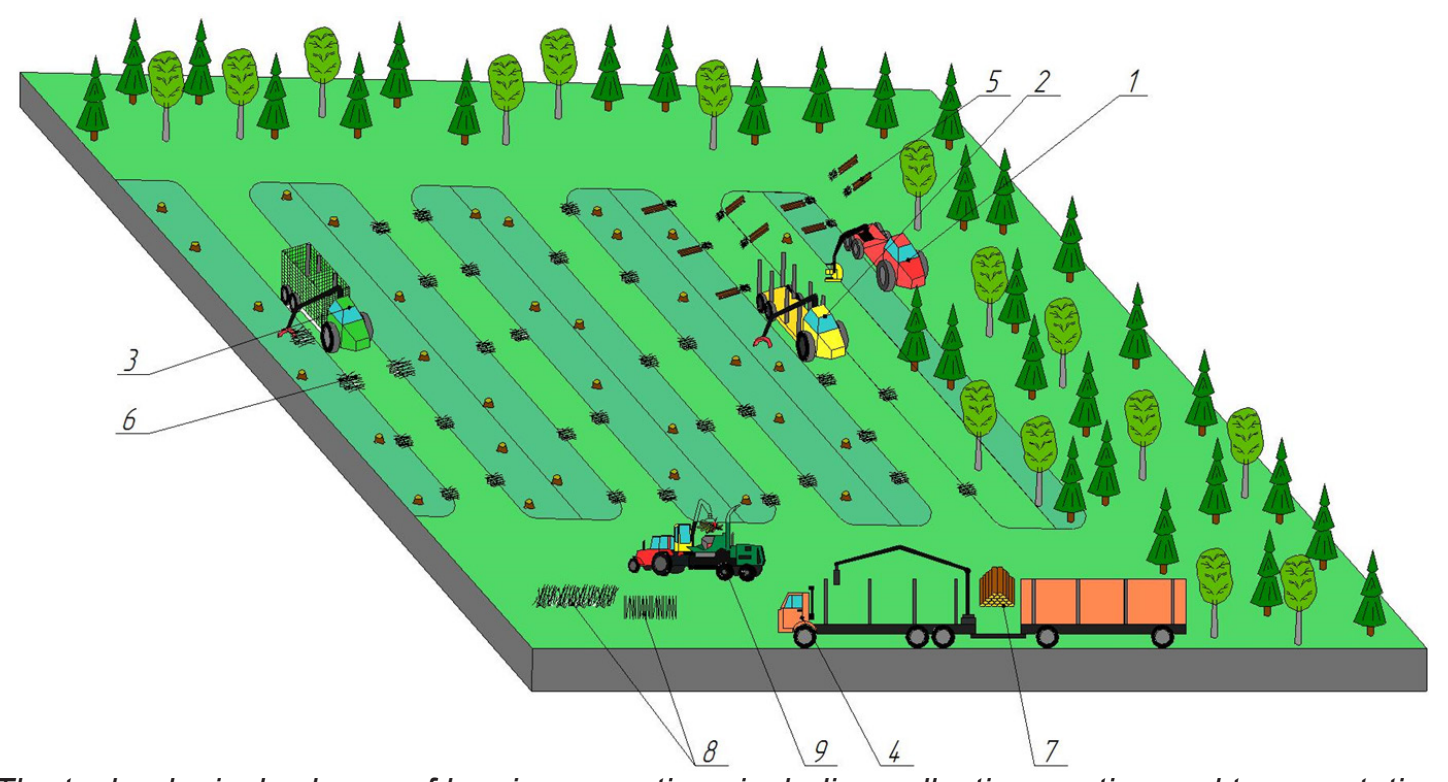

Figure 1: The technological scheme of logging operations including collection, sorting and transportation of logging residues: 1 - the harvester, 2 - the forwarder, 3 - sorting and transportation machine for logging residues, 4 - the road train, 5 - assortments at the felling site, 6 - felling residues at the felling site, 7 - the pile of assortments at the loading point, 8 - sorted felling residues at the loading point, 9 - the woodchipper

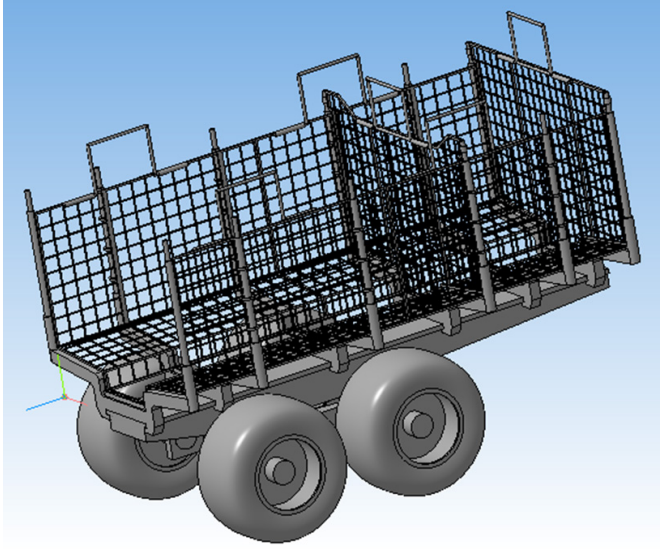

Figure 2: Removable body of sorting and transportation machine
For transportation of logging residues, the forwarder that is used for major works is equipped with a removable body that is fixed on the pillars of the cargo compartment. The transverse walls divide the body into compartments. The longitudinal, transverse sides are made of cellular metal to reduce the weight of the removable body, chipping of bark, needles and ash.

The manipulator is to be equipped with shearing head for cutting wood according to type (tops, large and small limbs, branches and green mass). This operation is possible when forwarder loads the branches into a compartment. The shearing heads of this type have the blade (guillotine) as cutting devices. With its help the branches are cut into pieces according to purpose. 
Logging residues that are sorted according to species and types are stacked in separate piles for further processing at the loading point or they are loaded into a road train for transportation to the terminal (timber warehouse) or to the consumer [17].

When the felling residues are at the loading point and they are shipped to the terminal or the consumer, the above removable body and a shearing head may be mounted on the road train.

\section{RESULTS}

The information and logical model [18] of the sorting and transportation machine (Fig. 3) with the indication of the components of the cycle time $\mathrm{T}_{\mathrm{C}}$ was developed for modeling of the technological process. The cycle is a set of operations necessary for sorting, collection, transportation and unloading of logging residues.

Before departure operator identifies and mounts the re-

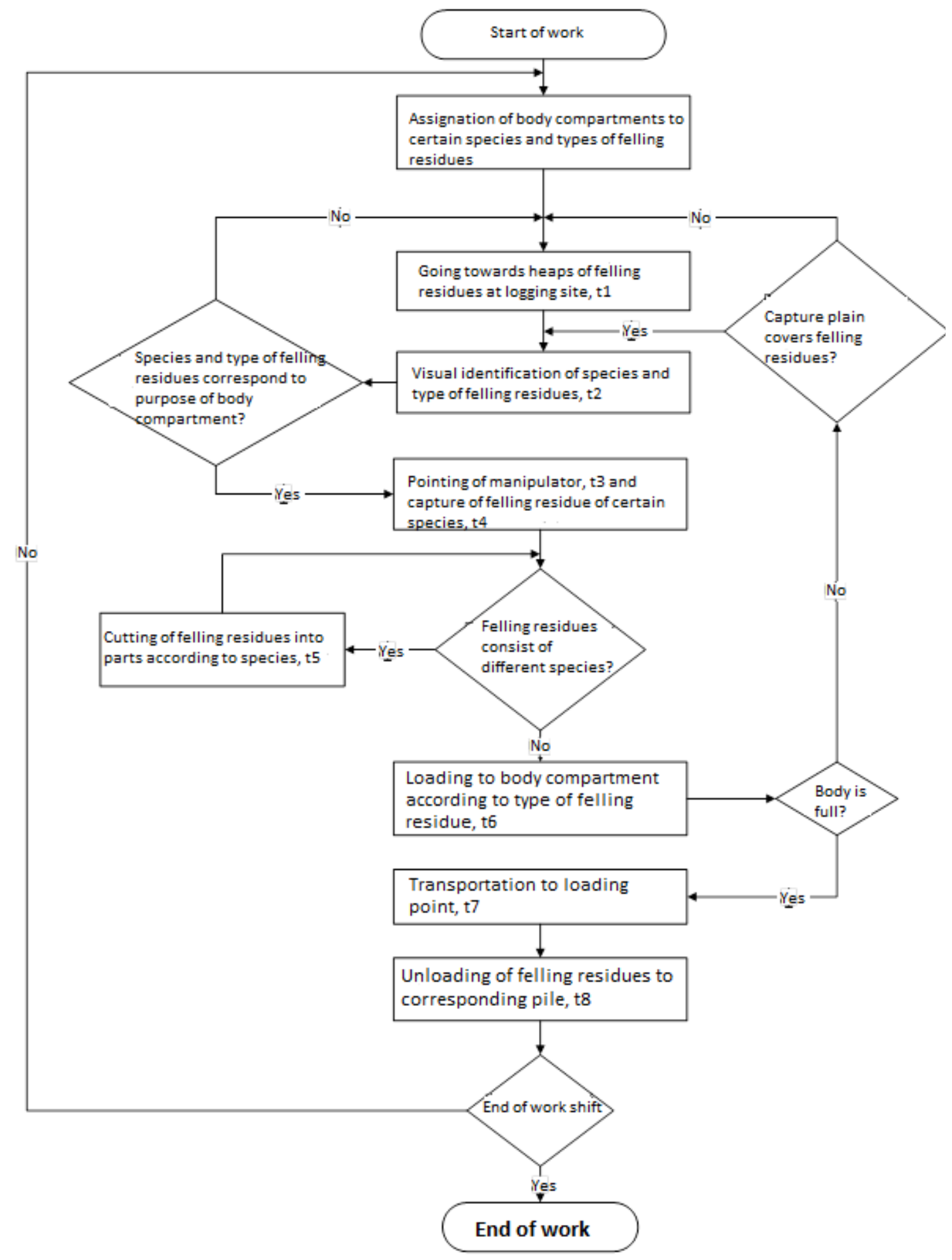

Figure 3: Information-logical model of the process of collection, sorting and transportation of felling residues 
quired number of compartments. Each compartment is conditionally set for certain species and types of logging residues. The operator points the cutting grab bucket on logging residues while going along the skid road of a logging area at each stop. The operator of the sorting and transportation machine shall visually determine the species and type of logging residues and their parts: long butt, tops, limbs, branches and green mass. Afterwards, the tops, limbs and branches of logging residues shall be cut by the cutting grab bucket according to the diameter dimensions depending on what is available in logging residues: tops, large branches, small branches, twigs, green mass.

The logging residues that are processed and sorted by types and sizes shall be taken to separate compartments of the body. When filling compartments of the body the sorted logging residuals shall be delivered to the loading point of the logging area and placed in separate piles.

On the basis of information and logical models of components and cycle time, the formula for calculating the performance shall be determined. Designations of the components of the cycle time $\left(T_{C}\right)$ in the information and logical model: $t_{1}$ is a period of time, during which the machine moves to heaps of logging residues, sec; $t_{2}$ is a period of time for determination of species and type of logging residues in a heap, sec; $t_{3}$ is a period of time for pointing of a manipulator to logging residues, sec; $t_{4}$ is a period of time for capture of logging residues with a cutting grab bucket, sec; $t_{5}$ is a period of cutting of residuals with a cutting grab bucket, sec; $t_{6}$ is period of time for movement of the grab bucket with logging residues and loading into the body compartment, sec; $t_{7}$ is time for transportation of logging residues to a loading point, sec; $t_{8}$ is period of time for unloading of logging residues, sec. Performance per shift, $\mathrm{P}_{\mathrm{s}}$ of sorting and transportation of logging residuals by sorting and transportation machine is calculated according to the formula:

$$
P s=\frac{\left(T-t_{f_{p}}\right) \cdot \varphi \cdot V k}{T C}
$$

where $\mathrm{T}$ is the shift time, sec;

$t_{f p}$ is the final preparatory time, sec;

$\varphi$ is the labor utilization coefficient;

$V_{K}$ is the volume of the body of the sorting and transportation machine, $\mathrm{m}^{3}$.

The components of cycle time are summarized in the formula for determining productivity. At the same time, the indicators $t_{3}, t_{4}$, and $t_{6}$ are multiplied by the number of techniques for loading of logging residues to fill the entire body, which is equal to the ratio of the volume of a body to the average volume of logging residues loaded per one time. The time taken to cut the logging residues $\left(t_{5}\right)$ is multiplied by the average number of cuts when filling the body of a truck. The number of cuts depends on the type and number of harvested logging residues and on the diameter and length of the knots and tops.
$\mathrm{T}_{\mathrm{s}}=\mathrm{t}_{1}+\mathrm{t}_{2}+\left(\mathrm{t}_{3}+\mathrm{t}_{4}+\mathrm{t}_{6}\right)^{*}+\mathrm{t}_{5}{ }^{*} \mathrm{n}+\mathrm{t}_{7}+\mathrm{t}_{8}$

where $v$ is the average volume of felling residues to be loaded per one time, $\mathrm{m}^{3}$;

$\mathrm{n}$ is the average number of cuts of felling residues during loading, pcs.

The main factors that affect the performance of sorting and transportation of felling residues at a cutting area are qualitative indicators of raw materials and qualification of operator.

\section{DISCUSSION}

The proposed technology and equipment will allow to sort felling residues for more efficient use. According to the authors, the proposed technical solution will be harmoniously introduced in the existing logging technological process. The proposed information and logical model and the calculation formula for performance will allow to plan the operation of machine with the greatest efficiency.

The results of these studies are necessary for improvement of technological processes of recycling of felling residues.

\section{CONCLUSION}

According to the results of the studies, several conclusions could be drawn up.

1. Logging residues are to be sorted according to species and types for efficient use.

2. Collecting and sorting of felling residues during the assortment logging should be carried out in the sorting and transportation machine on the basis of the forwarder that is used for main works.

3. Operation of sorting and transportation machine can be analyzed by sequential information logical and mathematical modeling.

4. The formula for calculation of the capacity of collection, sorting and transportation of logging residues that are suitable for practical use was obtained.

\section{ACKNOWLEDGEMENT}

The reported study was funded by Russian Foundation for Basic Research, Government of Krasnoyarsk Territory, Krasnoyarsk Regional Fund of Science, to the research project: «Research and modeling of economic development of the forest industry in the region in the context of climatic conditions and resource potential», grant No. 18-410-240003, The project «Development and implementation of effective technology for integrated processing of logging residue» was funded by Krasnoyarsk Regional Fund of Science. 


\section{REFERENCES}

1. Bezrukih Yu. A., Medvedev S. O., Alashkevich Yu. D., Mokhirev A. P. (2014). Rational nature resource management in the conditions of sustainable development of the economy of industrial enterprises of the timber complex. Economics and Enterprise. No. 12-2. pp. 994-996.

2. Mokhirev, A., Zyryanov, M., Ryabova, T., \& Vititnev, A. [2019]. Evaluation of possibility of obtaining woodchips from wood residues. Journal of Applied Engineering Science, 17(2), 140-143.

3. Vasiliev S. B., Piatkin V. I., Shegelman I. R. (2001). Technique and technology for production of chips in the timber industry: monograph. - Petrozavodsk: Publ. by Petrozavodsk State University. P. 100.

4. Gerasimov Y., Senko S., T. Karjalainen (2013). Nordic forest energy solutions in the Republic of Karelia. Forests. No. 4. 945-967.

5. Karha K. (2007). Production and Use of Wood Chips: Improving Supply Chains. Wood Energy UNECE/ FAO Workshop, Belgrade, Serbia. p. 68.

6. Heikkila J., Tanttu J. V., Lindblad J., Siren M., Asikainen A. (2006). Harvesting alternatives and cost factors of delimbed energy wood Metsanduslikud Laitila, Uurimused - Forestry Studies. No. 45. 49-56.

7. T. Karjalainen, A. Asikainen, J. Ilavsky, R. Zamboni, K-E. Hotari, D. Röser (2004). Estimation of Energy Wood Potential in Europe. Working Papers of the Finnish Forest Research Institute. 43.

8. Mikhaylov K.L., Gushchin V.A., Tarakanov A.M. (2016) Collection and Processing of Logging Residual and Firewood in a Felling Area. Lesnoy zhurnal (Forestry journal), no. 6, pp. 98-109. DOI: 10.17238/ issn0536-1036.2016.6.98

9. Vaatainen K. (2007). Wood fuel procurement methods and logistics in Finland. Wood fuel production for small scale use. University Eberswalde. P. 28.

10. Helmisaari H.S., Hanssen K.H., Jacobson S., Kukkola M., Luiro J., Saarsalmi A., Tamminen P., Tveite B. (2011) Logging Residue Removal after Thinning in Nordic Boreal Forests: Long-Term Impact on Tree Growth. Forest Ecology and Management, 2011, vol. 261, no. 11, pp. 1919-1927.
11. Victor D., Yueh L. (2010) The New Energy Order. Foreign Affairs, vol. 89, no. 1, pp. 61-73.

12. Heift R. (2000). Wykorzystanie odpadow pochadzenia roslirmego do celow energetycznych. Recuklace odpadu TV, VSB TU Ostrava. 165 - 173.

13. Mohirev A.P., Zyryanov M. A. (2015). The technology of logging operations with sorting of logging residuals. Systems. Methods. Technology. No. 3. 118-122.

14. Mokhirev A. P., Mammatov V. O., Urazaev A. P. (2015). Modeling of the technological process of work of logging machines. International Scientific Research. No. 3 (24). 72-74.

15. Sukhanov Yu. V., Gerasimov Yu. Yu., Seliverstov A. A., Sokolov A. P. (2011). Technological chains and systems of machines for collecting and recycling of wood biomass into fuel chips during continuous logging in assortments. Systems. Methods Technology. No. 4. 101-107.

16. Smirnov, M., Shirnin, Y., Shirnin, A., \& Andrianov, Y. [2019]. Research into the process of loading wood assortments by a tractor-mounted hydraulic manipulator of a tractor-trailer train. Journal of Applied Engineering Science, 17(3), 373-378.

17. Mokhirev A. P. (2016). Modeling of the process of operation of the machine for sorting and transportation of logging residues at the logging area. System. Methods. Technology. No. 1 (29). P. 89-94. DOI: 10.18324/2077-5415-2016-1-89-94

18. Rukomoynikov K. P. (2013). Simulation modelling of mutually agreed work of sets of adaptive modular timber machines. Bulletin of the MSFU "Forest Bulletin". No. 3 (95). P. 154-159. 